cerebrovascular disease would make intervention in the knee irrelevant or that the patient's diabetes needs control before the gall bladder is removed.

- Some control and balance of remuneration will be necessary so that those with the specialised techniques can earn a good living but not exploit the community with outrageous fees. Audit would be easily achieved by video recordings of each procedure stored in the hospital computer.

There is a precedent for high quality technology in the heart and lung bypass work of perfusion technicians. Although they do not have a formal medical training, they are required to assume major responsibility in the highly technical management of the heart and lung machine and react quickly should any malfunction develop.

Consideration should be given to special training for OK surgery that would lessen the burden on the taxpayer but would be entirely appropriate for the work involved. The current three year BSc course in general anatomy, physiology, and pathology would be a suitable start, followed by a three year training in the area of OK surgery that the student wishes to embrace. Having obtained a diploma in OK surgical technology the students would be able to practise on their own provided that there was cover from a more widely trained specialist. They would be paid according to experience.

There would still be a need for orthodox medical education and surgical specialisation with special arrangements to allow and encourage appropriate training for a country surgeon or a surgeon in a developing country, where there was no access to highly specialised equipment. On the medical side a similar training would be needed for the generalist physician who would need to see every patient referred for OK surgery. A more specialised training would be required, much on the lines of that already available, for a small number of specialist surgeons familiar with old fashioned techniques who would supervise the $\mathrm{OK}$ technical surgeons.

Without careful planning along these lines many expensive mistakes could be made.

\title{
Why me?
}

\section{J Stuart Horner}

To join that select group who have survived an observed cardiac arrest prompts many questions, not least, "Why me?" During my subsequent inpatient stay I saw two patients who failed to survive in apparently more favourable circumstances. I had been waiting to give a lecture at Kingston Postgraduate Medical Centre when a sudden nystagmatic movement of the house roofs opposite gave a brief premonitory warning before I subsided gently into the arms of my colleagues. I was placed in the semiprone position. In all cases of collapse cardiac arrest must first be excluded and this dictum was quickly followed. Resuscitation was started and the crash team called. Thirty minutes later I was admitted to the intensive care unit allegedly conscious, but my first recollection is of an insistent voice demanding to know if I knew where I was. Wherever I was, I was as reluctant to respond to the voice as someone in a comfortable warm bed is reluctant to respond to an insistent alarm clock. Once awake I was immediately able to give complicated instructions about my next of kin. Clearly no brain damage had resulted.

I was not short of explanations for the incident yet they seemed not to tally with my own experience. "You were anxious about the lecture." My telephone call to the centre to reassure that, despite my late arrival, the lecture would start on time was reinterpreted to imply that I was unnecessarily rushed. The determination of all the medical staff to ensure that I received the best possible care and the caring concern of the nursing staff simply confirmed my conviction that the NHS is the best place to be in a crisis. Arrangements were made for my transfer to St George's Hospital and this happened only five days later. Because of the ambulance dispute I was asked to make my own arrangements, which was perhaps unwise and undoubtedly hazardous. The ambulance workers would have agreed to my transfer if management could have been persuaded to make a suitably equipped vehicle available. Once I was settled in my Nightingale ward ambulatory cardiac monitoring was quickly resumed.

After the cardiac catheterisation the medical answer to my question was quickly forthcoming. Extensive coronary artery disease unsuitable for angioplasty meant that only a coronary bypass operation would relieve the electrically unstable heart. Yet this diagnosis itself was hard for an epidemiologist to bear. I have none of the conventional risk factors, being known locally as a "non-smoking, teetotal, fitness fanatic." Despite regular reminders from both the health authorities for which I have worked that the alleviation of stress should figure prominently in the health programmes I have advocated, I remain unconvinced that it is even an important factor. The term seems to mean different things to different people. If it means leading a busy life with many and varied engagements during a long working day I plead guilty. If, as I have always understood, it means the conflict of being trapped within circumstances over which you have little or no control it has no relevance to my own lifestyle. Decision making has never presented any problems for me and while others comment on the responsibilities I carry they do not intrude on those aspects of my life from which they should be properly excluded.

\section{Enjoyable camaraderie}

The camaraderie of a male surgical ward is an experience I will treasure. My medical background was quickly discovered-why else should I be about to speak to a group of doctors unless one of their number or a salesman? Fellow patients tried, unsuccessfully, to persuade one patient to accept the operation for which he had been admitted but now feared more than the risk of dying. Patients not making a determined attempt to recover were demoted to secondary status while each encouraged the other to yet greater efforts in the recovery process.

When my own day of operation dawned it began at a leisurely pace only to be transformed into frantic activity as my consultant insisted that I should be returned to my original place on the operating list. To submit myself into the total care of others was a novel but not unpleasant experience. I tried to do as I was told and to cooperate fully. My reward was freedom from pain and rapid mobilisation. Recovery after the operation was hampered by atrial flutter which left me breathless and exhausted on my bed. I felt I had let my fellow patients down but I need not have worried. In 
the final 24 hours after it had finally gone away they readily accepted me back and rejoiced with me at my unexpected discharge.

I have never made any secret of my strong belief in the saving grace of Jesus. It is inevitable therefore to turn to my Christian values for an answer to my question. The providential circumstances of the arrest itself together with no less than 10 subsequent unusual coincidences leave me in no doubt that the hand of God was on me throughout this experience. If, as Jeremiah asserts, God is able to replace our hearts of stone with living hearts that can share eternity with Him it is not difficult to believe that through the marvels of modern cardiac surgery $\mathrm{He}$ can replace a tired heart with one able to cope with all the demands made on it. The spiritual effect of the experience on me has been profound. Whatever state I was in during my arrest it presumably bears some relationship to death. Yet there were no heavenly choirs. I experienced no dissociation, when one becomes a spectator to the attempts being made to restore one's life. The state itself was not unpleasant and the requirement to return from it was distinctly unwelcome.

It is difficult to believe that I was not rescued for a purpose. Yet discerning that purpose is just as difficult as the earlier question. There is still much to be done as chairman of the medical ethics committee. Public health physicians have never been more desperately needed to introduce a note of sanity into the crazy products of political dogma known as the NHS review. Above all, with both children planning to marry in 1990 and a recognition of my BMA work due to be presented at Bournemouth, there were major reasons why if someone was to recover from a cardiac arrest it should have been me. Perhaps I should not struggle too hard for reasons but rather rejoice that a loving God was pleased to give me a new and exciting life through the dramatic events which occurred on 27 February.

\section{Thanks for caring}

\section{Jane Hollyhead}

It is no fun being in hospital at Christmas, especially when you are 18 , but that is what happened to me last year. I had been admitted a few days before suffering from myasthenia gravis and thyrotoxicosis. I was having trouble swallowing and had speech difficulties. The only available bed was in an orthopaedic ward where many of the ladies seemed to be having hip operations. Most of the staff did not understand about my disease or realise that I could not speak when asked a question. The first day I was moved twice around the ward and then eventually to a medical ward. By this time I was really frightened because my swallowing and breathing were getting worse and I felt so alone. I had been prescribed steroids and a muscle toning tablet but I couldn't swallow them very well and this upset me. The nurses gave me a notebook and pen to write down anything I needed. That night an elderly lady opposite me died. The screens were not pulled around her bed properly so I could see and hear what was happening. This was my first night in hospital and I found it a harrowing experience.

After two days my condition suddenly got worse. During the night I kept telling the night staff that I could not breathe properly and they sat me up and gave me a warm drink. Next morning I suffered a respiratory arrest and was rushed into the intensive care unit and ventilated. My lungs had burst so I had to have lung drains attached as well as all the usual tubes and lines which you depend on when you are unconscious. When I came round and was aware of where I was I found the staff were great. The day staff always arrived smiling and cheerful. They turned the radio up if my favourite pop song came on and when I was taken off the ventilator two of them washed my hair and sat me up ready to surprise my Mum and Dad.

\section{Too many bed baths}

As Christmas eve got nearer and I knew I wouldn't be going home I was depressed but the staff kept cheering me up and talking to me about all the things that were going on in the hospital. They even turned up with false noses on on Christmas eve. One complaint though - all those bed baths and bed changing - I must have been the cleanest person that Christmas.

By Christmas eve afternoon I had had all the tubes except one lung drain removed, and I was on my way to a medical ward to spend my Christmas. I was given a sideroom with its own toilet so I was glad of the privacy. They were all older people in the main ward so it was great to be on my own with a portable television. The staff decorated the room with streamers and one dressed up as Father Christmas and gave us all a present.

My treatment was continuing all this time, part of it being plasmapheresis biweekly. I found this traumatic, partly because it was a new machine in the renal unit and most of the staff were learning how it worked and partly because I had to have calcium injections. These had to be given very slowly as I had had a reaction to them and I was always frightened that I would react again. I had fresh plasma given to me once and I reacted to that and had to have an injection. If anything was going to happen it happened to me. Most of the time the treatment left me feeling shattered.

The day I had my second lung drain taken out I had a scan to see if there was any abnormality of my thymus gland. I found this painful as I had to lie with my arms stretched above my head for over half an hour. I was still in pain from the drain and my muscles were

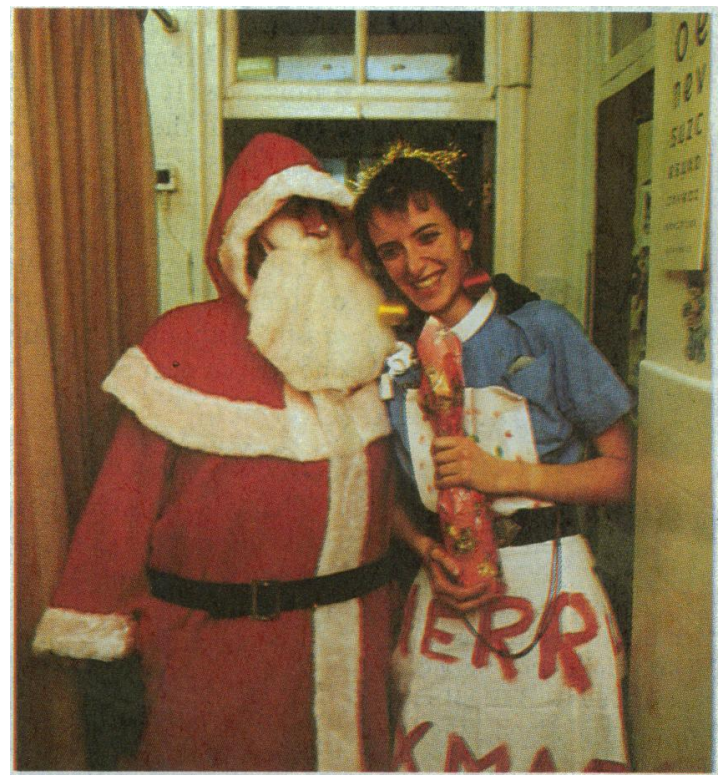

At Christmas Santa works a one in two rota, to make being in hospital more fun for patients 